\title{
Swift heavy ion irradiation induced phase transformation in calcite single crystals
}

\author{
H. Nagabhushana a,*,1, B.M. Nagabhushana ${ }^{\mathrm{b}}$, B.N. Lakshminarasappa ${ }^{\mathrm{c}}$, Fouran Singh ${ }^{\mathrm{d}}$, \\ R.P.S. Chakradhar ${ }^{\mathrm{e}}$ \\ a Department of PG Studies in Physics, Govt. Science College, Tumkur-572 103, India \\ ${ }^{\mathrm{b}}$ Department of Chemistry, M.S. Ramaiah Institute of Technology, Bangalore-560 054, India \\ ${ }^{\mathrm{c}}$ Department of Physics, Bangalore University, Bangalore-560 056, India \\ ${ }^{\mathrm{d}}$ Inter University Accelerator Centre, Aruna Asaf Alimarg, New Delhi - 110 067, India \\ e Glass Technology Lab, Central Glass and Ceramic Research Institute (CSIR), Kolkata- 700 032, India
}

\section{A R T I C L E I N F O}

\section{Article history:}

Received 27 May 2009

Received in revised form

16 July 2009

Accepted 30 July 2009 by P. Sheng

Available online 3 August 2009

\section{PACS:}

87.64je

80.00jh

Keywords:

A. Quasicrystals

C. Dislocations and disclinations

D. Phase transitions

E. Atom, molecule, and ion impact

\begin{abstract}
A B S T R A C T
Ion irradiation induced phase transformation in calcite single crystals have been studied by means of Raman and infrared spectroscopy using $120 \mathrm{MeV} \mathrm{Au}{ }^{9+}$ ions. The observed bands have been assigned according to group theory analysis. For higher fluence of $5 \times 10^{12}$ ion $/ \mathrm{cm}^{2}$, an extra peak on either side of the $713 \mathrm{~cm}^{-1}$ peak and an increase in the intensity of $1085 \mathrm{~cm}^{-1}$ peak were observed in Raman studies. FTIR spectra exhibit extra absorption bands at $674,1589 \mathrm{~cm}^{-1}$ and enhancement in bands at 2340 and $2374 \mathrm{~cm}^{-1}$ was observed. This might be due to the phase transformation from calcite to vaterite. The damage cross section $(\sigma)$ for all the Raman and FTIR active modes was determined. The increase of FWHM, shift in peak positions and appearance of new peaks indicated that calcite phase is converted into vaterite.
\end{abstract}

(c) 2009 Elsevier Ltd. All rights reserved.

\section{Introduction}

When swift heavy ions (SHI) pass through a solid target, a considerable amount of energy is transferred by the collisions with the electrons of the target material, resulting in transient high energy densities along the ion paths. The knocked out electrons, in turn, either dissipate their energy by collisions with other electrons or by electron-phonon coupling. High energy densities are known to be a prerequisite for phase transitions, which have occasionally been found to occur along swift heavy ion tracks [1,2]. Calcium carbonate occurs in three main crystalline polymorphs (calcite, aragonite, and vaterite), in two hydrated crystal forms (calcium carbonate monohydrate and calcium carbonate hexahydrate), and also as an amorphous material [3]. Calcite is the most abundant form and is widely distributed in the earth's crust followed by aragonite and vaterite. From the thermodynamic viewpoint, calcite is more stable than the other two structures at room

\footnotetext{
* Corresponding author. Tel.: +91 080 23146895; fax: +91 08162260220.

E-mail addresses: bhushanvl@rediffmail.com (H. Nagabhushana), sreechakra72@yahoo.com (R.P.S. Chakradhar).

1 Mobile No: 9945954010.
}

temperature and atmospheric pressure, whereas vaterite is the most unstable polymorph which is rarely seen. Calcium carbonate has been widely used as a model system for investigating inorganic precipitation reaction or crystallization due to its important industrial application in paints, plastics, rubber, paper, cosmetics, and food industries [4].

Calcite has a trigonal structure with two molecules per unit cell. The calcium ions and the carbon atoms of the carbonate ions all lie on the trigonal axis and the orientations of the two carbonate ions are staggered relative to each other so that there is a center of symmetry. The structure of calcite is of greater interest because of a number of important mineral constituents of sedimentary rocks, including magnesium and iron bearing carbonate, having structures that are identical with or closely related to the calcium pattern [5]. Therefore, the structure of calcite serves as a logical starting point in describing the structure of such materials.

Some studies have been carried out on phase transformation of calcite to other phases including ball milling [6], temperature, pressure [7,8], hydrothermal synthesis [9] etc. Previous works [7,8] from IR and Raman studies on calcite crystals have demonstrated that carbonate internal modes were sensitive to the phase changes from temperature and pressure and could effectively be used to probe the structural transitions. However, to the best of our 
knowledge phase transformation of calcite using swift heavy ion irradiation has not been reported. In the present work, an attempt has been made to study $120 \mathrm{MeV} \mathrm{Au}^{9+}$ ion irradiation induced effects on $\mathrm{CO}_{3}^{2-}$ internal modes in the $\mathrm{CaCO}_{3}$ single crystals by means of Raman and FTIR spectroscopy.

\section{Experimental}

Transparent calcite single crystals of $\sim 1 \times 1 \times 2 \mathrm{~mm}^{3}$ are cleaved in a big block procured from Alminrock minerals, Bangalore, India. The samples are irradiated at room temperature over an area $1 \times 1 \mathrm{~cm}^{2}$ by scanning the ion beam using an electromagnetic scanner. The vacuum in the irradiation chamber is maintained at $\approx 10^{-6}$ Torr. $\mathrm{Au}^{9+}$ ions of $120 \mathrm{MeV}$ are used to irradiate the calcite single crystals from 15-UD Pelletron at Inter University Accelerator Centre, New Delhi [10] with appropriate beam current of 2 Pna. The fluences used are $1 \times 10^{11}-5 \times 10^{12}$ ions $/ \mathrm{cm}^{2}$. Raman spectroscopic studies are carried out on the pristine (without irradiation) and $\mathrm{Ag}^{9+}$ ion irradiated crystals using a Renishaw In via Raman spectrometer with $785 \mathrm{~nm}$ He-Cd laser operating at $150 \mathrm{~W}$ power. Leica DMLM optical microscope equipped with $50 \mathrm{X}$ objective lens is used to determine the analyzed part of the sample. Three to five accumulations for each position with an accumulation time of $10 \mathrm{~s}$ are maintained for all the measurements. The spectra are calibrated using $520 \mathrm{~cm}^{-1}$ line of silicon wafer. The data acquisition and analysis are carried out using WIRE 2.0 software. The FTIR measurements of pristine and ion irradiated calcite single crystals are carried out using Bruker FTIR instrument from $400-3500 \mathrm{~cm}^{-1}$.

\section{Results and discussion}

Raman spectroscopy is known to be a nondestructive material characterization technique. It provides a unique way of probing surface and structural properties of ion beam modified materials. According to factor group analysis 27 optical modes will be distributed (lattice modes, internal modes) [11]. In Raman spectrum of calcite, a total of five fundamental vibrational modes, two lattice modes and three internal modes are expected to be active [12] along with overtone of the infrared active $2 v_{2}$ mode at $1759 \mathrm{~cm}^{-1}$. Fig. 1 shows the Raman spectra of pristine and $120 \mathrm{MeV} \mathrm{Au}^{9+}$ ion irradiated calcite single crystals for a fluence of $1 \times 10^{11}-5 \times 10^{12}$ ions $/ \mathrm{cm}^{2}$. The pristine spectrum has five fundamental bands located at $\sim 152,280,713,1085$ and $1485 \mathrm{~cm}^{-1}$ along with extra bands located at 1118, 1203, 1291, 1382, 1542, 1659,1759 and $1841 \mathrm{~cm}^{-1}$. These fundamental bands are in good agreement with those reported in the literature [13-16]. From factor group analysis of calcite, internal $\mathrm{A}_{1 \mathrm{~g}}$ mode $\left(v_{1}\right.$, symmetric stretch) of the carbonate anion located at $\sim 1085 \mathrm{~cm}^{-1}$ is the strongest feature. The weak lines located in the regions of 1485 and $713 \mathrm{~cm}^{-1}$ are due to internal $E_{g}$ modes corresponding to the in-plane bending $\left(v_{4}\right)$ and anti-symmetric stretching $\left(v_{3}\right)$ modes of $\mathrm{CO}_{3}^{2-}$ ions. The two small bands at 152 and $280 \mathrm{~cm}^{-1}$ have been assigned to translational and rotational $\left(E_{g}\right)$ modes respectively. The overtone band at $\sim 1759 \mathrm{~cm}^{-1}$ is an $A_{1 g}$ internal mode corresponding to out-of-plane bending $\left(v_{2}\right)$. The strong Raman vibrational band at $1085 \mathrm{~cm}^{-1}$ corresponding to the case in which all the $\mathrm{CO}_{3}^{2-}$ groups vibrate as in identical phases [17]. The band at $1542 \mathrm{~cm}^{-1}\left(v_{1}\right)$ which is produced by the stretching vibration of $-\mathrm{C}=\mathrm{C}-$ double bonds, and at $1118 \mathrm{~cm}^{-1}\left(v_{1}\right)$ stretching of $-\mathrm{C}-\mathrm{C}-$ single bonds [18].

Liu et al. [19] have studied the phase transformation of calcite by Raman spectra in hydrostatic pressure environment. They observed most intense band at $\sim 1085 \mathrm{~cm}^{-1}$ ( $\mathrm{A}_{1 \mathrm{~g}}$ mode), two sets of doubly degenerate, internal $E_{g}$ modes (712 and $\left.1434 \mathrm{~cm}^{-1}\right)$ and

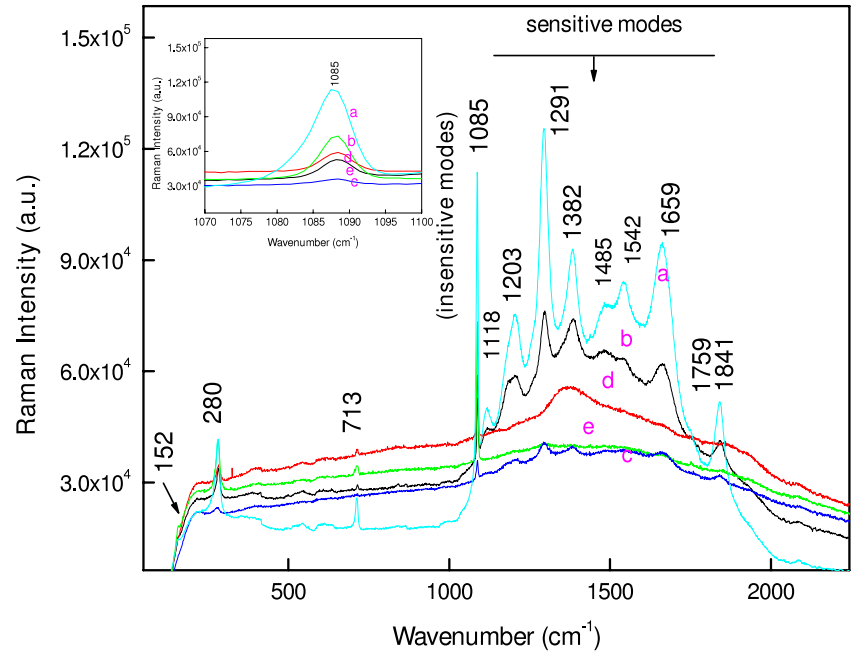

Fig. 1. Raman spectra of (a) Pristine (b) $1 \times 10^{11}$ ions $\mathrm{cm}^{-2}$ (c) $5 \times 10^{11}$ ions $\mathrm{cm}^{-2}$ (d) $1 \times 10^{12}$ ions cm $\mathrm{cm}^{-2}$ (e) $5 \times 10^{12}$ ions cm $\mathrm{cm}^{-2}$ (inset: The $1085 \mathrm{~cm}^{-1}$ peak increase as the $\mathrm{Au}^{9+}$ ion fluence $5 \times 10^{12}$ ions $\mathrm{cm}^{-2}$ (dotted line)).

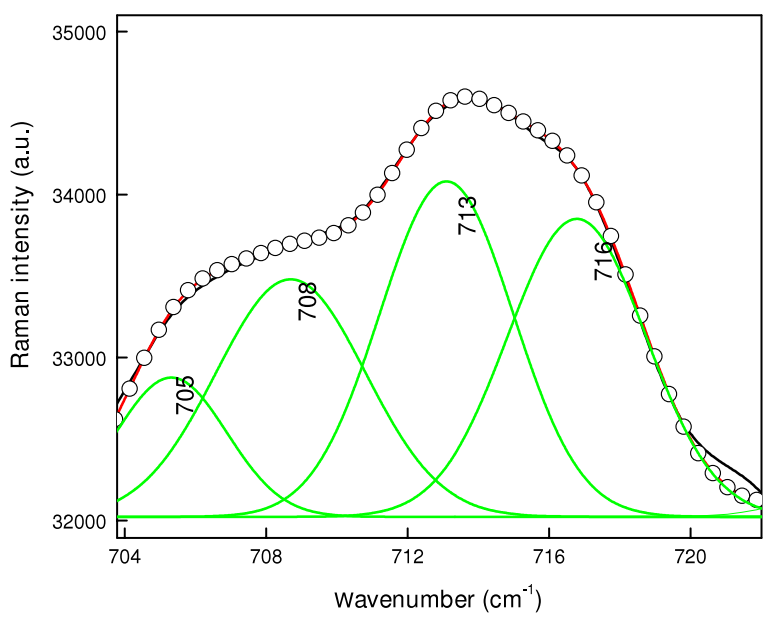

Fig. 2. Deconvolution of $713 \mathrm{~cm}^{-1}$ peak $\left(5 \times 10^{12}\right.$ ions $\left.\mathrm{cm}^{-2}\right)$.

external $E_{g}$ or lattice modes (282 and $156 \mathrm{~cm}^{-1}$ ). The external modes are associated with liberation of the $\mathrm{CO}_{3}^{2-}$ ions in primitive cell around axes normal to the $\mathrm{C}_{3}$ axis and translations of the $\mathrm{CO}_{3}^{2-}$ ions normal to the $\mathrm{C}_{3}$ axis, respectively. At high pressures, the bands at 1440 and $715 \mathrm{~cm}^{-1}$ splits into doublets. This is an indication of phase transformation. Krishnamurthi et al. [20] have studied the calcite crystal by Raman spectroscopy. The strong Raman band at $1092 \mathrm{~cm}^{-1}$ corresponding to the case in which all the $\mathrm{CO}_{3}^{2-}$ group vibrate in identical phase. The strong Raman active modes $1092 \mathrm{~cm}^{-1}$ would combine with weak modes 162, 288, 716 and $1437 \mathrm{~cm}^{-1}$ to give sharply defined symmetrical values.

In the present study, it is observed that the intensity of the sensitive Raman modes decreases with increase of ion fluence $\left(1 \times 10^{11}-5 \times 10^{12}\right.$ ions $\left./ \mathrm{cm}^{2}\right)$. With increase of ion fluence to $5 \times 10^{12}$ ions $/ \mathrm{cm}^{2}$, the sensitive Raman bands completely disappear and the modes at 1085 (inset of Fig. 1) and $713 \mathrm{~cm}^{-1}$ start growing with additional features arising at $713 \mathrm{~cm}^{-1}$ peak. In order to identify the extra bands produced after irradiation, we deconvoluted the peak using ORIGIN 8.0 software. The results indicate that the asymmetric peak is nicely presented as a mixture of three Gaussian peaks at 705,708 and $716 \mathrm{~cm}^{-1}$ respectively (two from lower wave number side and one from higher wave number side) (Fig. 2).

Increase of FWHM and area under the peak, peak shift towards higher wave number side as well as presence of new peaks at 


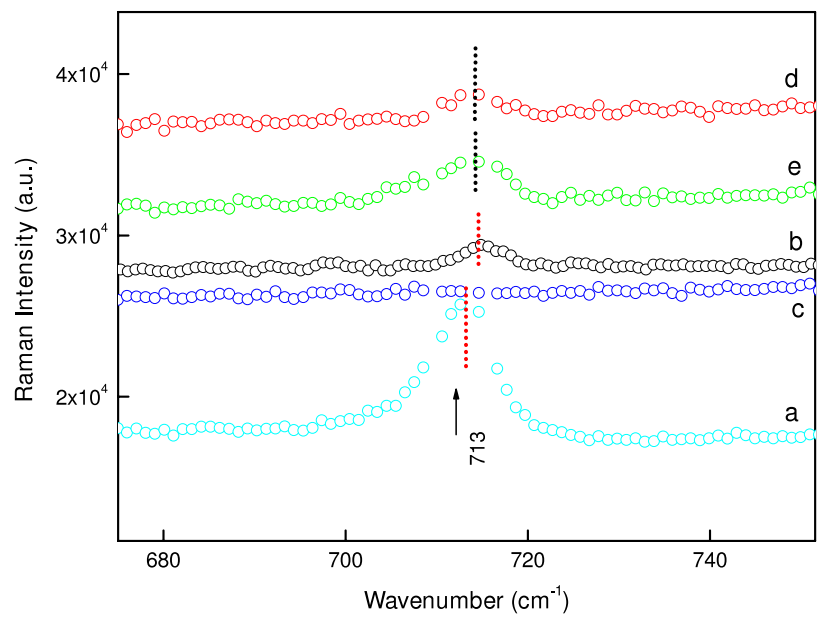

Fig. 3. Peak shift $\left(713 \mathrm{~cm}^{-1}\right)$ with the increase of $\mathrm{Au}^{9+}$ ion irradiation (a) Pristine (b) $1 \times 10^{11}$ ions $\mathrm{cm}^{-2}$ (c) $5 \times 10^{11}$ ions $\mathrm{cm}^{-2}$ (d) $1 \times 10^{12}$ ions $\mathrm{cm}^{-2}$ (e) $5 \times 10^{12}$ ions $\mathrm{cm}^{-2}$.

$713 \mathrm{~cm}^{-1}$ were observed (Fig. 3) with increase of ion fluence. This is a strong evidence of phase transformation of calcite. The decrease in intensity of sensitive Raman bands with increase of ion fluence might be due to breakage of $\mathrm{CO}_{3}^{2-}$ ions due to amorphization/ either change in the crystal phase or surface amorphization. Amorphization occurs because each incident ion creates one or several different cascades which become amorphous as a result of the rapid quenching and these cascades eventually overlap to form an amorphous solid [19].

Benyagoub et al. [21] have studied phase transformation induced in pure zirconia by high energy heavy ions with ${ }^{58} \mathrm{Ni}(550$, $300,135 \mathrm{MeV})$ and ${ }^{76} \mathrm{Ge}(300 \mathrm{MeV})$. The phase transformation was studied by means of XRD and Raman spectroscopy. The experiments clearly confirm that the irradiation of pure zirconia with swift heavy ions can induce a crystalline phase transformation from monoclinic to tetragonal phase. It is demonstrated that this transformation is triggered only when the deposited electronic energy loss is in excess of a threshold $\sim 13 \mathrm{keV} \mathrm{nm}^{-1}$. If electronic energy loss is less than the threshold, amorphization, defect and track formation were observed. From transport of ions in matter (TRIM) calculations, when the energy of the incident ions is of few $\mathrm{keV}$ then the nuclear energy loss $\left(S_{n}\right)$ are significant as compared to electronic energy loss $\left(S_{e}\right)$. In the present experiment we have used $120 \mathrm{MeV}$ energy for irradiation and the nuclear energy is dominant over the electronic energy transfer interactions in the near surface region. Therefore, there is a possibility of phase transformation of calcite.

FTIR studies have been carried out to confirm the phase transformation/surface amorphization. Fig. 4 shows the FTIR spectra of pristine and $\mathrm{Au}^{9+}$ ion irradiated calcite for a fluence of $5 \times 10^{12}$ ions $/ \mathrm{cm}^{2}$. The main absorption peaks observed at $\sim 707,873,1413,2505,2876,2983 \mathrm{~cm}^{-1}$. In the FTIR spectra, out-of-plane bending $\left(v_{2}\right)$, the asymmetric stretching $\left(v_{3}\right)$ and inplane bending $\left(v_{4}\right)$ modes of $\mathrm{CO}_{3}^{2-}$ ions and found to be active as predicted from the factor group analysis [17]. Besides the first order internal modes the $v_{1}+v_{4}, 2 v_{2}+v_{4}, 2 v_{3}$ combinational modes are observed. The presence of non-splitting peaks $v_{2}$ and $v_{4}$ in the pristine sample indicate the presence of calcite structure in the sample.

It is observed from the figure, in ion irradiated sample, an extra absorption bands at 674 and $1589 \mathrm{~cm}^{-1}$, at the same time the other absorption bands completely destructed with increase of ion fluence. The destruction of these modes with irradiation may further enhance the amorphous in nature of the sample. The decrease in (Raman and FTIR) intensity might

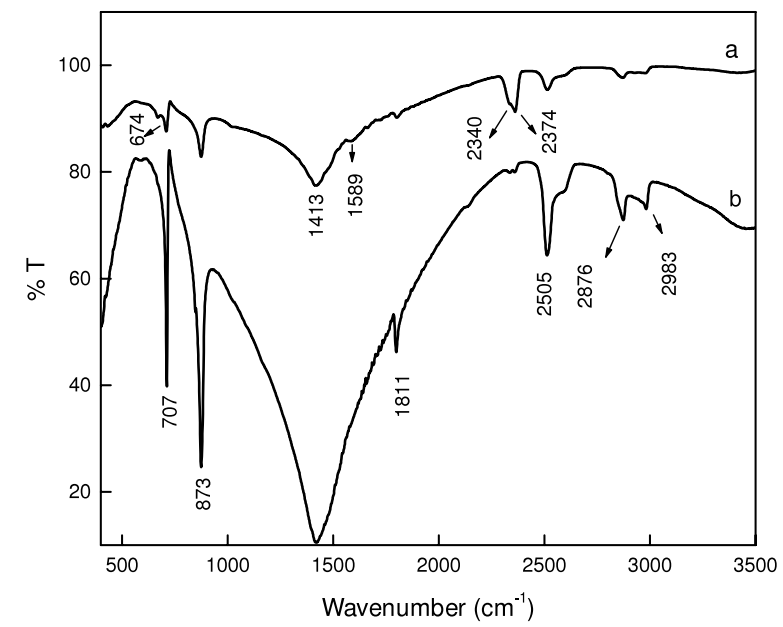

Fig. 4. FTIR spectra of (a) $\mathrm{Au}^{9+}$ ion irradiated $\left(5 \times 10^{12}\right.$ ions $\left.\mathrm{cm}^{-2}\right)$ (b) Pristine.

Table 1

Observed frequencies in Raman and FTIR spectra of calcite.

\begin{tabular}{cll}
\hline Raman & FTIR & Assignment \\
\hline $152(\mathrm{~m})$ & - & LM calcite \\
$280(\mathrm{~m})$ & - & LM calcite \\
$713(\mathrm{w})$ & $707(\mathrm{w})$ & $v_{4}-\mathrm{CO}_{3}$ calcite \\
$1085(\mathrm{~s})$ & $873(\mathrm{~m})$ & $v_{2}-\mathrm{CO}_{3}$ calcite \\
$1485(\mathrm{w})$ & $1413(\mathrm{~s}, \mathrm{~b})$ & $v_{3}-\mathrm{CO}_{3}$ calcite \\
$1759(\mathrm{w})$ & $1811(\mathrm{sh})$ & $v_{1}+v_{4}$ \\
- & $2505(\mathrm{~m})$ & $2 v_{2}+v_{4}$ \\
- & $2776-2983(\mathrm{~m})$ & $2 v_{3}$
\end{tabular}

m: medium, w: weak, s: strong, b: broad, sh: shoulder, LM: Lattice mode $v_{1}$-symmetric stretching, $v_{2}$-symmetric bending, $v_{3}$-asymmetric stretching, $v_{4}$ asymmetric bending.

be attributed to the destruction of the surface chemical species $\left(\mathrm{CO}_{3}^{2-}\right)$ because of the energy deposited through $S_{e}$ during SHI irradiation and formation of non-radiative recombination centers at higher fluences. The irradiation effects may lead to the restructuring of the chemical species because of the energy deposited through electronic energy loss during the process of SHI irradiation and formation of ion induced defects leading to non-radiative recombination centers. These two processes are simultaneous consequences of irradiation and they compete with each other [22]. The degradation/enhancement in Raman peaks intensity might be due balance between these two effects. The mode assignments of fundamental bands in FTIR and Raman studies are given in Table 1.

Shivakumar et al. [23] have studied the synthesis of vaterite phase by direct precipitation of glycine and L-alanine. They observed a characteristic $\mathrm{CO}_{3}^{2-}$ peak at $1417 \mathrm{~cm}^{-1}$ and $\mathrm{C}-\mathrm{O}$ stretching at 1084 and $713 \mathrm{~cm}^{-1}$ in FTIR measurements. In pure vaterite characteristic $\mathrm{CO}_{3}^{2-}$ at $1417 \mathrm{~cm}^{-1}$ splits into 1478 and $1406 \mathrm{~cm}^{-1}$. The $\mathrm{C}-0$ stretching appear at $744 \mathrm{~cm}^{-1}$ in pure vaterite and common $\mathrm{C}-\mathrm{O}$ stretching at around 1084 and $713 \mathrm{~cm}^{-1}$ due to mixed phase. In vaterite phase the peaks at 1084 and $671 \mathrm{~cm}^{-1}$ are more prominent when compared to calcite.

The damage cross section $(\sigma)$ for the destruction of the $\mathrm{CaCO}_{3}$ can be observed from the decrease in the Raman peak intensity as a function of $\mathrm{Au}^{9+}$ ion dose. Following the analysis suggested in [24] we assume that the areal density $\mathrm{N}$ of the $\mathrm{CaCO}_{3}$ molecule remaining after irradiation with an ion dose $\mathrm{D}$ is given by

$\mathrm{N}=\mathrm{N}_{0} \exp (-\sigma \mathrm{D})$

where $\sigma$ is the cross section. For the Raman measurements, $\mathrm{N}$ is proportional to the integrated Raman intensity Hence, for the Raman measurements a plot of $\log _{10}[\mathrm{I}(\mathrm{D}) / \mathrm{Io}]$ versus dose where 
I(D) is the intensity of a particular Raman peak after a dose D and Io is the intensity of the corresponding peak in the pristine sample, should yield a straight line whose slope is the cross section, $\sigma$ for the destruction of $\mathrm{CaCO}_{3}$ by the ion beam. The intensity of the different Raman bands after a given dose I(D), normalized to the intensity of this peak for pristine sample Io is plotted as $\log _{10}[\mathrm{I}(\mathrm{D}) / \mathrm{Io}]$ versus ion fluence. The Raman data when plotted in this way do indeed follow a straight-line dependence. The linear fits to Raman data yield a damage cross section $(\sigma)$ of different Raman modes. The errors have been estimated on the basis of lines of worst fit taking into account the uncertainties in each of the data points. It is noticed that all the fundamental Raman active modes having different damage cross sections/different sensitiveness for ion irradiation. The sensitive Raman modes such as 1118,1203 , 1291, 1382, 1485, 1542, 1659, 1759 and $1841 \mathrm{~cm}^{-1}$ have highest damage cross section $\left(\sim 2.2 \times 10^{12} \mathrm{~cm}^{2}\right)$ i.e. the most sensitive to get damaged by ion beam. On the other hand the $1085,280 \mathrm{~cm}^{-1}$ modes have lowest damage cross section $\left(1.0 \times 10^{-12} \mathrm{~cm}^{-2}\right)$. This is the least affected vibrational mode. Atomic Force microscopy (AFM) and glancing angle X-ray diffraction (G-XRD) are effective tools for examining surface modifications/ phase transformation of the sample.

\section{Conclusions}

The Raman and Infrared spectroscopic studies of $120 \mathrm{MeV} \mathrm{Au}^{9+}$ swift heavy ion irradiated calcite single crystals have been studied in the fluence range $1 \times 10^{11}-5 \times 10^{12} \mathrm{ions} / \mathrm{cm}^{2}$. The characteristic Raman bands observed at $\sim 152,280,713,1085$ and $1485 \mathrm{~cm}^{-1}$ respectively. In FTIR spectrum, the main absorption bands observed at $\sim 707,873,1413$ and $1811 \mathrm{~cm}^{-1}$ respectively. It is observed that intensity, area, FWHM of the Raman and FTIR sensitive peaks decreases with increase in $\mathrm{Au}^{9+}$ ion fluence. For higher fluence of $5 \times 10^{12} \mathrm{ion} / \mathrm{cm}^{2}$, an extra peak on either side of the $713 \mathrm{~cm}^{-1}$ peak and increase in intensity of $1085 \mathrm{~cm}^{-1}$ peak was observed in Raman studies. Whereas in FTIR studies, extra absorption bands at $674,1589 \mathrm{~cm}^{-1}$ and enhancement in absorption bands at 2340 and $2374 \mathrm{~cm}^{-1}$ was observed. This might be due to the phase transformation from calcite to vaterite. The damage cross section $(\sigma)$ for all the Raman and FTIR active modes were determined and found to be different for different modes.
The increase of FWHM, shift in peak positions and appearance of new peaks indicated that calcite phase is converted into vaterite.

\section{Acknowledgments}

The authors wish to express their sincere thanks to Dr. D.K. Avasthi, Nuclear Science Centre (NSC), New Delhi, for useful discussion, besides his constant help and encouragement in this work. One of the authors (H.N.) thanks to NSC for the award of Fellowship under UFUP scheme. Dr. RPSC thanks Dr. H.S. Maiti, Director CGCRI and Dr. R. Sen, Head GTL lab for their constant support and encouragement.

\section{References}

[1] Lakhwant Singh, K.S. Samra, Ravinder Singh, Indra Solania, D.K. Avasthi, J. Non. Cryst. Solids 354 (2008) 41.

[2] H. Nagabhushana, B. Umesh, B.M. Nagabhushana, B.N. Lakshminarasappa Fouran Singh, R.P.S. Chakradhar, Spectrochim. Acta A 73 (2009) 637.

[3] Hua Tang, Jiaguo Yu, Xiufeng Zhao, Mater. Res. Bull. 44 (2009) 831.

[4] E. Dalas, P. Klepetsanis, P.G. Koutsoukos, Langmuir 15 (1999) 8322

[5] Danhua Lou, Fengjiu Sun, Lijuan Li, Chin. Opt. Lett. 5 (2009) 370.

[6] A. Devarajan, M. Abdul Khadar, K. Chattopadhyay, Mat. Sci. Eng. A 452 (2007) 395.

[7] Philippe Gillet, Claudine Biellmann, Bruno Reynard, Paul McMillan, Phys Chem. Mineral. 20 (1993) 1.

[8] M.Y. Fong, M. Nicol, J. Chem. Phys. 54 (1971) 579

[9] Z. Nan, X. Chen, Q. Yang, X. Wang, Z. Shi, W. Hou, J. Colloid Interface Sci. 325 (2008) 331.

[10] G.K. Mehta, A.P. Patro, Nucl. Instrum. Methods A 268 (1998) 334.

[11] J. Urmos, S.K. Sharma, F.T. Mackenzie, Am. Mineral. 76 (1991) 641.

[12] W.B. White, The Carbonate Minerals, Mineralogical Society, London, 1974.

[13] Akio Yammoto, Yuji Shiro, Hiromu Murata, Bull. Chem. Soc. Jpn. 47 (1974) 265.

[14] C.G. Kontoyannis, N.V. Vagenas, Analyst 125 (2000) 251.

[15] H.N. Rutt, J.H. Nicola, J. Phys. C Solid State 7 (1974) 4522.

[16] S. Gunasekaran, G. Anbalagan, Spectrochim. Acta A 68 (2007) 656.

[17] S. Gunasekaran, G. Anbalagan, Spectrochim. Acta A 69 (2008) 1246

[18] S. Saito, M. Tasumi, J. Raman Spectrosc. 14 (1983) 310.

[19] Lin-Gun Liu, T.P. Mernagh, Am. Minerol. 75 (1990) 801.

[20] D. Krishnamurthi, Proc. Indian Acad. Sci. A 46 (1957) 183.

[21] A. Benyagoub, F. Couvreur, S. Bouffard, F. Levesque, C. Dafour, E. Paumier, Nucl. Instrum. Methods B 175-177 (2001) 417.

[22] T.M. Bhave, S.S. Hullavarad, S.V. Bhoraskar, S.G. Hegde, D. Kanjilal, Nucl. Instrum. Methods B 156 (1999) 121.

[23] C. Shivakumara, Pretam Singh, Asha Gupta, M.S. Hegde, Mater. Res. Bull. 41 (2006) 1455.

[24] S. Prawer, K.W. Nugent, S. Biggs, D.G. McCulloch, W.H. Leong, A. Hoffman, R. Kalish, Phys. Rev. B 52 (1995) 841. 